\title{
Associations of adiponectin receptor 2 (AdipoR2) gene polymorphisms and AdipoR2 protein expression levels with the risk of colorectal cancer: A case-control study
}

\author{
LEI ZHOU ${ }^{1 *}$, HAI-FENG ZHANG ${ }^{2 *}$, WU NING ${ }^{1}$, XIN SONG $^{1}$, XIN LIU $^{1}$ and JI-XI LIU ${ }^{3}$ \\ ${ }^{1}$ Department of General Surgery, China-Japan Friendship Hospital, Beijing 100029; \\ ${ }^{2}$ Department of General Surgery, Ruian People's Hospital, Wenzhou, Zhejiang 325200; \\ ${ }^{3}$ Department of Gastroenterology, China-Japan Friendship Hospital, Beijing 100029, P.R. China
}

Received July 29, 2016; Accepted May 4, 2017

DOI: $10.3892 / \mathrm{mmr} .2017 .7115$

\begin{abstract}
The aim of the present study was to investigate the associations between adiponectin receptor 2 (AdipoR2) gene polymorphisms, AdipoR2 protein expression levels and the risk of colorectal cancer (CRC). From April 2012 to May 2015, 281 CRC patients (case group) admitted to the China-Japan Friendship Hospital and 325 healthy control subjects (control group) were recruited for the study. Peripheral venous blood samples were collected and the DNA was extracted. Genotyping was performed using denaturing high-performance liquid chromatography in the condition of partial degeneration. Linkage disequilibrium and haplotype were analyzed using SHEsis analysis software. AdipoR2 protein expression levels were detected by immunohistochemistry and logistic regression analysis was performed to determine the risk factors of CRC. The distribution of the TT genotype of AdipoR2 rs10773989 and the CC genotype of AdipoR2 rs1044471 was higher in the case group than in the control group $(\mathrm{P}<0.05)$. The AdipoR2 rs10773989 polymorphism was associated with the degree of tumor infiltration in $\mathrm{CRC}(\mathrm{P}<0.05)$ and the AdipoR2 rs1044471 polymorphism was associated with the degree of differentiation and Dukes' staging in CRC $(\mathrm{P}<0.05)$. The CT haplotype was identified as a protective factor, while the TC haplotype was a risk factor in a healthy population. AdipoR2 protein expression was associated with the degree of differentiation, Dukes' staging, degree of tumor infiltration and lymphatic metastasis in CRC
\end{abstract}

Correspondence to: Dr Ji-Xi Liu, Department of Gastroenterology, China-Japan Friendship Hospital, 2 East Yinghuayuan Street, Chaoyang, Beijing 100029, P.R. China

E-mail: jixiliu2013@163.com

*Contributed equally

Key words: colorectal cancer, adiponectin receptor 2, gene polymorphism, immunohistochemistry, risk factor, haplotype, rs10773989, rs1044471 (all $\mathrm{P}<0.05$ ). Logistic regression analysis demonstrated that the TT genotype of AdipoR2 rs10773989 and CC genotype of AdipoR2 rs1044471 were independent risk factors for CRC. The AdipoR2 rs10773989 and rs1044471 polymorphisms may be correlated with the susceptibility to CRC. In addition, the TC haplotype and AdipoR2 positive expression may increase the risk of CRC.

\section{Introduction}

Colorectal cancer (CRC) is a leading cause of cancer morbidity and mortality worldwide, and it is estimated that there are $\sim 1.2$ million newly diagnosed patients annually and $>600,000$ patients succumbing to the disease globally (1). In addition, CRC has been long prevalent in western populations, accounting for $\sim 142,570$ novel cases and 51,370 cancer-associated mortalities in the United States in 2010 (2). CRC is characterized by late clinical presentation and a relatively rapid disease progression, which is the primary underlying reason for increased mortality and morbidity in patients suffering from this malignancy (3). However, advances in treatment modalities, including surgery, radiation therapy and chemotherapy, have steadily improved the 5-year survival rate for CRC (4). Etiologically, interactions of genetic and environmental factors are considered to be significant in the pathogenesis of CRC (5). Certain epidemiological studies have reported that western dietary and behavior patterns, such as high fat, low fiber intake and deficiency of physical activity, which leads to obesity, insulin resistance and hypertension, were the predominant reason for increasing incidence of CRC, particularly in developing countries $(6,7)$. However, the associations between important adipokines, specifically between adiponectin (ADIPOQ) and its receptors (AdipoRs) and the risk of CRC have been demonstrated in a number of epidemiological studies $(8,9)$.

ADIPOQ, secreted exclusively by adipocytes, is a peptide hormone and insulin-sensitizing adipokine including two receptors, AdipoR1 (abundant in skeletal muscle cells) and AdipoR2 (predominantly in the liver cells) (10). AdipoR2 is a protein, which in humans is encoded by the AdipoR2 gene (11). AdipoR2, possessing 7 transmembrane domains, 
mediates a number of metabolic processes, consisting of fatty acid oxidation and glucose uptake by ADIPOQ (12). Notably, AdipoRs have been observed to be expressed in human malignant cells, such as CRC, breast and prostate cancer, and to mediate the anticancer activities of ADIPOQ in the cells (13). Furthermore, certain single nucleotide polymorphisms (SNPs) in the AdipoR2 gene, such as rs1342387, rs1063538, rs266729 and rs1862513, may be associated with CRC risk (6,13-15). In addition, rs10773989 and rs1044471 in the AdipoR2 gene have been reported to be associated with various types of disease, such as type 2 diabetes, and prostate and gastric cancer (16-18). However, such associations between the SNPs in AdipoR2 and CRC remain controversial $(19,20)$. In the current study, a case-control study was performed to systemically evaluate the associations of AdipoR2 rs10773989 and rs1044471 SNPs and AdipoR2 protein expression levels with the risk of CRC.

\section{Materials and methods}

Ethical approval. The present study was approved by the Ethics Committee of China-Japan Friendship Hospital (Beijing, China). All study participants provided written informed consent and the study conformed to the Declaration of Helsinki (21).

Study subjects. From April 2012 to May 2015, a total of 281 blood samples ( $3 \mathrm{ml}$ each) were obtained from 281 hospitalized CRC patients from the China-Japan Friendship Hospital, who had been pathologically confirmed according to World Health Organization (WHO) guidelines. These 281 patients formed the case group (male, 165; female, 116; age range, 40-82 years; mean age, $60.40 \pm 10.40$ years) (22). The inclusion criteria were as follows: i) Patients with non-primary $\mathrm{CRC}$; and ii) patients that had received preoperative chemotherapy or radiotherapy. During the corresponding period, a total of 325 blood samples ( $3 \mathrm{ml}$ each) were collected from 325 healthy control subjects (male, 196; female, 129; age range, 44-91 years; mean age, 61.07 \pm 10.32 years), who had received a physical examination at the China-Japan Friendship Hospital, this group served as the control. The exclusion criteria were as follows: i) Healthy control subjects of a different ethnic background to the patients; ii) age differences between healthy control subjects and the patients $>3$ years; iii) healthy control subjects in sibship with the patients; iv) healthy control subjects with tumors or diseases of the digestive system. The two groups were matched according to age $(\mathrm{P}>0.05)$ and gender $(\mathrm{P}>0.05)$. Following resection, the $\mathrm{CRC}$ tissue samples from all of the patients were dehydrated and embedded in paraffin for immunohistochemistry. In addition, 20 adjacent normal colon mucosa tissue samples ( $>5 \mathrm{~cm}$ from the carcinoma) were randomly collected from the patients.

DNA collection and genotyping. Peripheral blood (3 $\mathrm{ml})$ was obtained in the morning from fasted CRC patients and healthy control subjects, respectively. The plasma was removed by centrifugation at 3,000 $\mathrm{xg}$ and room temperature for $15 \mathrm{~min}$, $3 \mathrm{ml}$ human erythrocyte lysate was added and mixed for $5 \mathrm{~min}$ to dissolve the erythrocyte and centrifuged at $10,000 \mathrm{x} \mathrm{g}$ for $30 \mathrm{sec}$ for leukocyte sedimentation. After the addition of cell lysate, DNA was extracted using a DNA kit (Qiagen
$\mathrm{GmbH}$, Hilden, Germany) according to the manufacturer's instructions. An ultraviolet spectrophotometer (UV2600; Zhengzhou Nanbei Instrument Equipment Co., Ltd, China) was used to determine the DNA content and absorbance ratio $\left(\mathrm{A} ; \mathrm{A}_{260} / \mathrm{A}_{280}\right)$, which was between 1.8 and 2.0. In the current study, rs10773989 and rs1044471 of the AdipoR2 gene were selected to evaluate their association with the risk of CRC. The amplification primers for AdipoR2 rs10773989 and rs1044471 were designed using Primer Premier 5.0 software (Premier Biosoft International, Palo Alto, CA, USA), and synthesized by Shanghai Sangon Biotechnology Co. Ltd. (Table I).

The reaction conditions of the polymerase chain reaction (PCR) were as follows: 35 Cycles of pre-denaturation at $94^{\circ} \mathrm{C}$ for $2 \mathrm{~min}$, denaturation at $94^{\circ} \mathrm{C}$ for $1 \mathrm{~min}$, annealing at $52^{\circ} \mathrm{C}$ for $1 \mathrm{~min}$, extension at $72^{\circ} \mathrm{C}$ for $1 \mathrm{~min}$, followed by a final extension at $72^{\circ} \mathrm{C}$ for $5 \mathrm{~min}$, then stored at $4^{\circ} \mathrm{C}$. Genotyping was performed using denaturing high-performance liquid chromatography (DHPLC) in the condition of partial degeneration, with column temperature of $59.3^{\circ} \mathrm{C}$ and a flow rate of the mobile phase of $0.9 \mathrm{ml} / \mathrm{min}$. The genotyping of rs10773989 was performed in two steps: i) The double-peak elution profile in DHPLC indicated heterozygotes (TC genotype) (Fig. 1A); and ii) the polymerase chain reaction (PCR) samples presenting a single-peak were mixed with an equal quantity of TT genotype sample confirmed by sequencing, and then genotyped by DHPLC, consequently, the single-peak elution profile indicated the TT genotype and the double-peak elution profile demonstrated the CC genotype (Fig. 1B). Mutation of the $\mathrm{T}$ and $\mathrm{C}$ allele was confirmed by sequencing, as presented in Fig. 1C. The genotyping of rs1044471 was also conducted in two steps: i) The double-peak elution profile in DHPLC indicated heterozygote (CT genotype; Fig. 2A); and ii) the PCR samples presenting a single-peak were mixed with an equal quantity of CC genotype sample, confirmed by sequencing, and then genotyped by DHPLC; consequently, the single-peak elution profile indicated the CC genotype and the double-peak elution profile suggested the TT genotype (Fig. 2B). Mutation of the T and C allele was confirmed by sequencing (Fig. 2C).

Immunohistochemistry. All collected tissue samples were fixed in $10 \%$ neutral buffered formalin, embedded in paraffin, sliced into 4- $\mu \mathrm{m}$ sections, and subjected to immunohistochemistry. The paraffin sections were baked, deparaffinized, dehydrated by successive soaking in dimethylbenzene, absolute ethyl alcohol, and 95 and $75 \%$ ethyl alcohol, and then washed in phosphate-buffered saline (PBS) three times. The tissue sections were immersed in antigen retrieval (AR) solution containing citric acid, and heated in a microwave oven for 12 min for AR. Subsequent to washing with PBS, $\mathrm{H}_{2} \mathrm{O}_{2}$ was added dropwise to block the peroxidase activity, and $50 \mu \mathrm{l}$ endogenous biological blocker (solution A) was added dropwise and incubated at room temperature for 13 min to block tissue protein. Solution A was removed and $50 \mu \mathrm{l}$ goat serum (solution B) was added and incubated at room temperature for $10 \mathrm{~min}$, then the serum was removed. Primary antibody, rabbit anti-human AdipoR2 monoclonal antibodies (50 $\mu \mathrm{l} /$ section; cat. no. BS-0611R; Beijing Biosynthesis Biotechnology Co., Ltd., Beijing, China) at a dilution of 1:300 were diluted in Tris-buffered saline containing $2.5 \%$ bovine serum albumin. 
Table I. Polymerase chain reaction primers for genotyping of adiponectin receptor 2 gene polymorphisms.

\begin{tabular}{lrc}
\hline Polymorphic locus & Primer sequence $\left(5^{\prime}-3^{\prime}\right)$ & Location \\
\hline $\begin{array}{l}\text { rs10773989 } \\
\text { Reverse }\end{array}$ & intron \\
Forward & ATTCCAGACAAAGCGGAAGT & 325 \\
rs 1044471 & CTGAAGACAATAAACCACAC & \\
Reverse & & intron \\
Forward & TTCCTAGACCAAGTACCTTAAG & 398 \\
\hline
\end{tabular}

$\mathrm{R}$, reverse; F, forward.

A
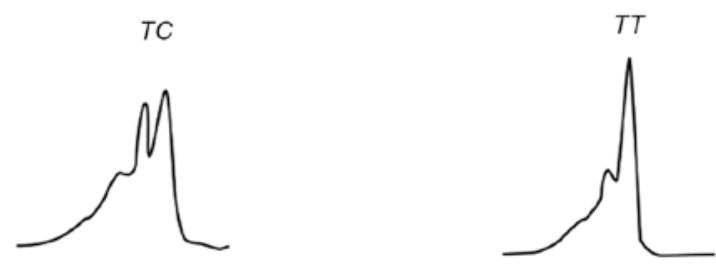

B
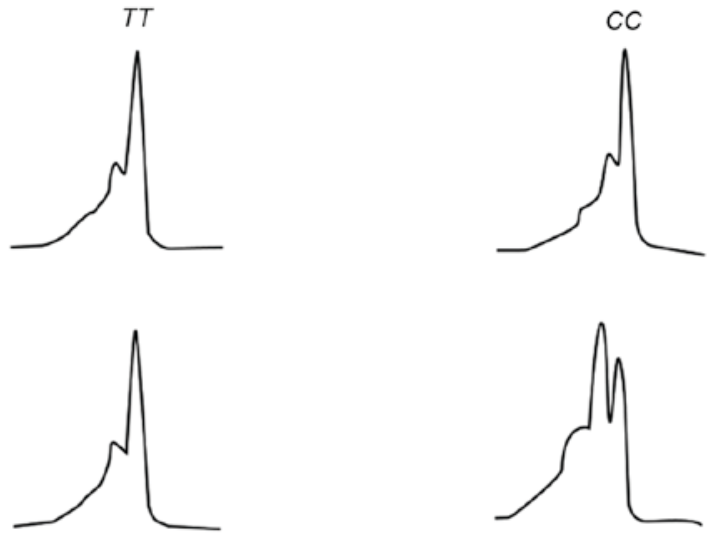

C
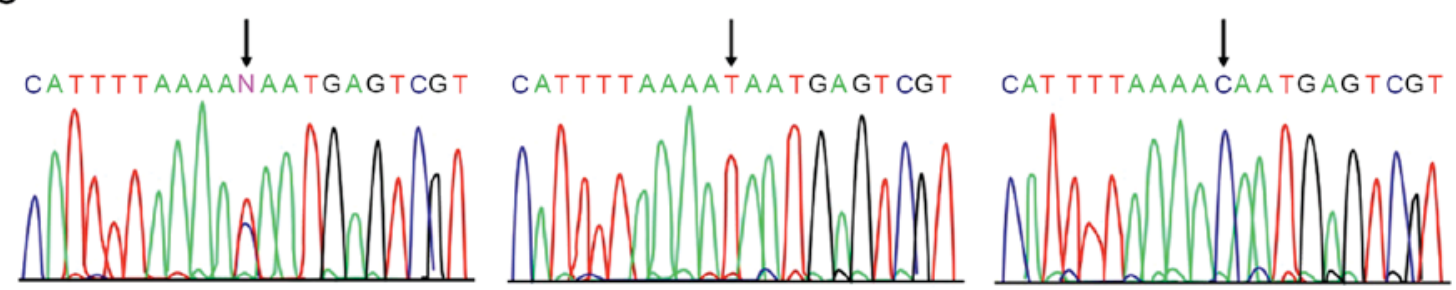

Figure 1. Denaturing high-performance liquid chromatography elution profiles of genotypes in rs10773989 and sequencing results of polymerase chain reaction products. (A) The double-peak elution profile indicated heterozygotes (TC genotype), and the single-peak elution profiles indicated the TT and CC genotype. (B) The single-peak elution profile indicated the TT genotype and the double-peak elution profile indicated the CC genotype. (C) A peak graph for sequencing of the $\mathrm{T}$ and $\mathrm{C}$ mutations.

Biotinylated goat anti-rabbit IgG (1:200; cat. no. BA-1000; Vector Laboratories, Inc., Burlingame, CA, USA) served as the secondary antibody. All sections were stained with 3,3'-diaminobenzidine for 3-10 min and then re-stained with hematoxylin.

The results of immunohistochemistry were observed at a magnification of x400 under an Olympus CKX41 inverted microscope, and analyzed using Image-Pro Plus v4.5 software (Media Cybernetics, Inc., Rockville, MD, USA) and the ZINO DH-CG 300 image analysis system (version 410; Beijing Daheng Image Vision Co. Ltd., Beijing, China). Eight high-power fields (HPFs) per section were randomly observed under the microscope (magnification, x400) with 100 cells per HPF counted. The staining results were semi-quantitatively scored (the score of the percentage of stained cells $x$ the score of staining intensity). The percentage of stained cells was scored as follows: 0 (negative) for $<5 \%$ stained cells; 1 (weak positive) for 6-20\% stained cells; 2 (positive) for $21-50 \%$ stained cells; 3 (strong positive) for $>50 \%$ stained cells. The staining intensity was scored as: 0 (negative) for no intensity; 1 (weak positive) for light yellow; 2 (positive) for pale brown; and 3 (strong positive) for sepia. The staining results were divided into four grades as follows: i) 0 , negative; ii) $1-3$, weak positive; iii) 4-6, moderate positive; iv) 7-9, strong positive (23).

Statistical analysis. Statistical software SPSS 21.0 (IBM Corp., Armonk, NY, USA) was used to analyze data. Enumeration data were presented as percentage or rate. The $\chi^{2}$ test was applied for comparison of the genotype frequency differences between groups, and verified if the allele frequency was in Hardy-Weinberg equilibrium (HWE). Odds ratio (OR) and its $95 \%$ confidence interval (CI) was used 
A
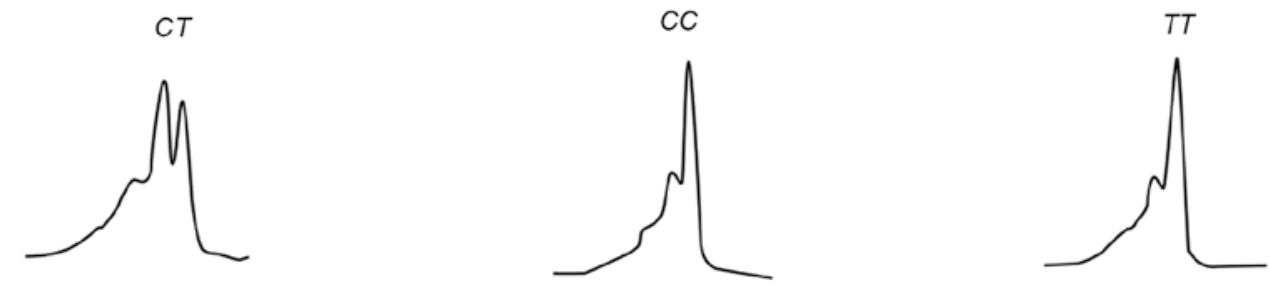

B
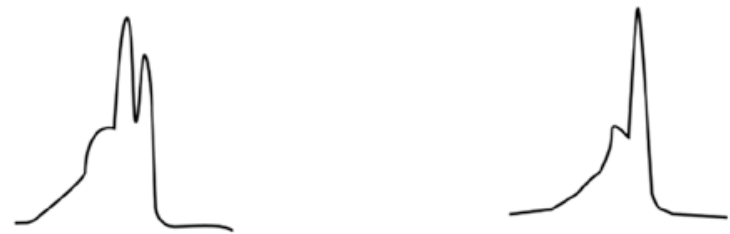

C

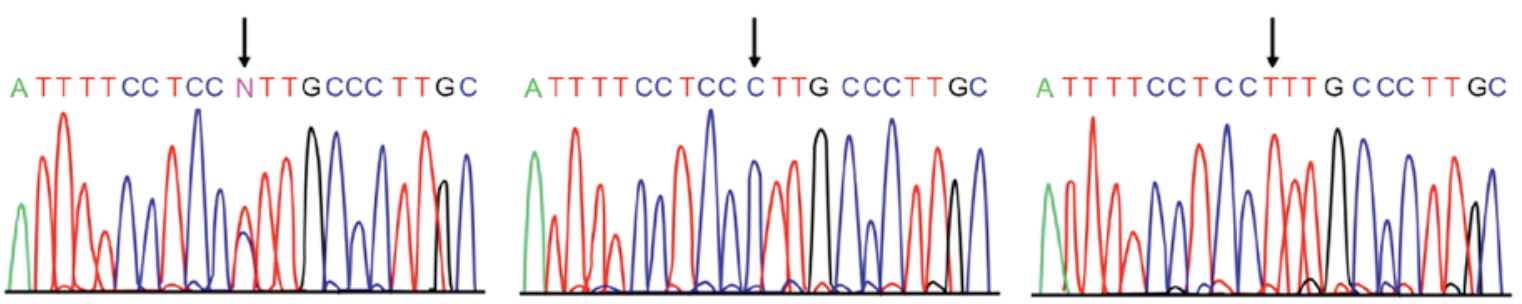

Figure 2. Denaturing high-performance liquid chromatography elution profiles of genotypes in rs1044471 and sequencing results of polymerase chain reaction products. (A) The double-peak elution profile indicated heterozygotes (CT genotype), and the single-peak elution profiles indicated the CC and TT genotype. (B) The single-peak elution profile indicated the CC genotype and the double-peak elution profile indicated the TT genotype. (C) A peak graph for sequencing of the $\mathrm{C}$ and $\mathrm{T}$ mutations.

to demonstrate the associations of various genotypes with CRC risk. The enumeration data was demonstrated as the mean \pm standard deviation, and the differences of genotype frequency between groups were compared using the independent samples t-test. The haplotype frequency of rs10773989 and rs1044471 was analyzed using SHEsis analysis software, an online software platform that estimates haplotype frequencies (http://analysis.bio-X.cn/SHEsisMain.htm) (24). The pathogenic factors of the patients were analyzed using multivariate non-conditioned logistic regression analysis and $\mathrm{P}<0.05$ was considered to indicate a statistically significant difference.

\section{Results}

Baseline characteristics of CRC patients and healthy control subjects. As presented in Table II, no significant differences in age, gender, smoking status, alcohol consumption, body mass index (BMI), total cholesterol (TC), triglyceride (TG), high-density lipoprotein cholesterol (HDL-C), or low-density lipoprotein cholesterol (LDL-C) were identified between the case group and the control group $(\mathrm{P}>0.05)$. A statistically significant difference was observed in tumor history between the case and control groups $(\mathrm{P}<0.05)$.

Correlations of AdipoR2 gene polymorphisms with the risk of $C R C$. The genotype distribution of polymorphic loci in the control group was calculated to be in HWE $(\mathrm{P}>0.05)$, indicating that the control subjects came from an equilibrium population and were therefore representative. As demonstrated in Table III, the frequencies of TC, CC, and TC + CC genotypes in AdipoR2 rs10773989 were 38.79, 12.10 and 50.89\%, respectively in CRC patients, and 46.46, 16.00 and $62.46 \%$, respectively in the healthy control subjects, indicating significant differences from the TT genotype frequencies in AdipoR2 rs10773989 $(\mathrm{P}<0.05)$. The frequencies of $\mathrm{T}$ and $\mathrm{C}$ alleles in AdipoR2 rs10773989 were 68.51 and $31.49 \%$, respectively in CRC patients and 60.77 and $39.23 \%$, respectively in healthy control subjects, which were significantly different $(\mathrm{P}<0.05)$. In AdipoR2 rs1044471, the frequencies of CT, TT, CT + TT genotypes in CRC patients were 30.60 , 3.60 and $34.20 \%$, respectively and were $38.15,6.77$ and $44.92 \%$, respectively, in the healthy control subjects which were statistically different from the $\mathrm{CC}$ genotype frequency $(\mathrm{P}<0.05)$. In addition, the frequencies of $\mathrm{C}$ and $\mathrm{T}$ alleles in AdipoR2 rs10773989 were 81.14 and $18.86 \%$, respectively in CRC patients and 74.15 and $25.85 \%$, respectively in the healthy control subjects, and were significantly difference $(\mathrm{P}<0.05)$.

Correlations of AdipoR2 gene polymorphisms with clinicopathological features of CRC patients. According to the degree of tumor infiltration, CRC patients were divided into a serosal breakthrough group $(n=219)$ and a non-serosal breakthrough group ( $\mathrm{n}=62)$. In AdipoR2 rs10773989, the frequencies of the TC + CC and TT genotypes were 33.33 and $66.67 \%$, respectively in the non-serosal breakthrough group, and 55.71 and $44.29 \%$, respectively in the serosal breakthrough group $\left(\chi^{2}=9.219 ; \mathrm{P}=0.002\right)$. No correlation was identified between the genotype distribution of AdipoR2 rs10773989 and other clinicopathological features ( $\mathrm{P}>0.05$; Table IV). According to 
Table II. Baseline characteristics of patients with colorectal cancer $(n=281)$ and healthy control subjects $(n=325)$.

\begin{tabular}{|c|c|c|c|c|}
\hline Characteristic & Case & Control & $t / \chi^{2}$ & P-value \\
\hline Age (years) & $60.40 \pm 10.40$ & $61.07 \pm 10.32$ & 0.794 & 0.427 \\
\hline Gender, n (\%) & & & 0.158 & 0.691 \\
\hline Male & $165(58.72)$ & $196(60.31)$ & & \\
\hline Female & $116(41.28)$ & $129(39.69)$ & & \\
\hline Smoking status, n (\%) & & & 0.293 & 0.588 \\
\hline Yes & $79(28.11)$ & $85(26.15)$ & & \\
\hline No & $202(71.89)$ & $240(73.85)$ & & \\
\hline Alcohol consumption, n (\%) & & & 0.553 & 0.457 \\
\hline Yes & $55(29.57)$ & $56(17.23)$ & & \\
\hline No & $226(80.43)$ & $269(82.77)$ & & \\
\hline Tumor history, n (\%) & & & 5.454 & 0.019 \\
\hline Yes & $30(10.68)$ & $18(6.15)$ & & \\
\hline No & $251(89.32)$ & $307(93.85)$ & & \\
\hline BMI $\left(\mathrm{kg} / \mathrm{m}^{2}\right)$ & $23.05 \pm 1.64$ & $22.85 \pm 1.68$ & 1.478 & 0.140 \\
\hline $\mathrm{TC}(\mathrm{mmol} / \mathrm{l})$ & $5.10 \pm 0.88$ & $4.98 \pm 0.72$ & 1.846 & 0.065 \\
\hline TG (mmol/l) & $1.84 \pm 0.96$ & $1.96 \pm 1.18$ & 1.359 & 0.174 \\
\hline LDL-C (mmol/l) & $2.58 \pm 1.07$ & $2.44 \pm 1.09$ & 1.590 & 0.112 \\
\hline HDL-C (mmol/l) & $1.34 \pm 0.36$ & $1.32 \pm 0.71$ & 0.427 & 0.669 \\
\hline
\end{tabular}

Data are presented as the mean \pm standard deviation or $\mathrm{n}$ number (percentage of total $\mathrm{n}$ number). BMI, body mass index; TC, total cholesterol; TG, triglyceride; HDL-C, high-density lipoprotein cholesterol; LDL-C, low-density lipoprotein cholesterol.

Table III. Correlations of adiponectin receptor 2 genetic polymorphisms (rs10773989 and rs1044471) with the risk of colorectal cancer in the case $(n=281)$ and control $(n=325)$ groups.

\begin{tabular}{lcccc}
\hline Genotype & $\begin{array}{c}\text { Case group, } \\
\mathrm{n}(\%)\end{array}$ & $\begin{array}{c}\text { Control group, } \\
\mathrm{n}(\%)\end{array}$ & $\begin{array}{c}\text { Odds ratio (95\% } \\
\text { confidence interval) }\end{array}$ & $\chi^{2}$ \\
\hline rs10773989 & & & & \\
TT & $138(49.11)$ & $122(37.54)$ & $1.567(1.108-2.216)$ & 6.485 \\
TC & $109(38.79)$ & $151(46.46)$ & $1.730(1.053-2.842)$ & 4.741 \\
CC & $34(12.10)$ & $52(16.00)$ & $1.606(1.161-2.221)$ & 8.238 \\
TC+CC & $143(50.89)$ & $203(62.46)$ & & 0.011 \\
T & $385(68.51)$ & $395(60.77)$ & $1.404(1.107-1.781)$ & 0.004 \\
C & $177(31.49)$ & $255(39.23)$ & & 7.864 \\
rs1044471 & $185(65.80)$ & $179(55.08)$ & & 0.005 \\
CC & $86(30.60)$ & $124(38.15)$ & $1.190(1.057-2.101)$ & 5.207 \\
CT & $10(3.60)$ & $22(6.77)$ & $2.274(1.047-4.937)$ & 5.509 \\
TT & $96(34.20)$ & $146(44.92)$ & $1.572(1.131-2.185)$ & 7.273 \\
CT TT & $456(81.14)$ & $482(74.15)$ & & 0.026 \\
C & $106(18.86)$ & $168(25.85)$ & $1.499(1.139-1.974)$ & 0.034 \\
T & & & & 8.405 \\
\hline
\end{tabular}

the degree of differentiation, CRC patients were classified into poorly differentiated $(n=126)$, moderately differentiated $(n=93)$ and well-differentiated $(\mathrm{n}=62)$ groups. In AdipoR2 rs1044471, the frequencies of CT + TT and CC genotypes were 39.68 and $60.32 \%$, respectively in the poorly differentiated group, 37.63 and $62.37 \%$, respectively in the moderately differentiated group, and 17.74 and $82.26 \%$, respectively in the well-differentiated group, demonstrating statistical significance in the frequencies of CT + TT and CC genotypes among the poorly, moderately and well-differentiated groups $\left(\chi^{2}=9.630 ; \mathrm{P}=0.008\right)$. According to Dukes' staging (25), patients were separated into stage A $(n=93)$, stage $B(n=123)$ and stage $C(n=65)$ groups. In AdipoR2 rs1044471, the frequencies CT + TT and CC genotypes in the stage A group were 41.94 and $58.06 \%$, respectively; 40.65 and 
Table IV. Correlation of adiponectin receptor 2 rs10773989 polymorphism with clinicopathological features of patients with colorectal cancer.

\begin{tabular}{|c|c|c|c|c|c|c|}
\hline \multirow[b]{2}{*}{ Feature } & \multicolumn{3}{|c|}{ Genotype } & \multirow[b]{2}{*}{ P-value } & \multirow[b]{2}{*}{$\mathrm{TC}+\mathrm{CC}$} & \multirow[b]{2}{*}{ P-value } \\
\hline & TT & $\mathrm{TC}$ & $\mathrm{CC}$ & & & \\
\hline \multicolumn{7}{|l|}{ Tumor diameter $(\mathrm{cm})$} \\
\hline$<5$ & 50 & 46 & 18 & \multirow[t]{2}{*}{0.187} & 64 & \multirow[t]{2}{*}{0.155} \\
\hline$\geq 5$ & 88 & 63 & 16 & & 79 & \\
\hline \multicolumn{7}{|l|}{ Histological type } \\
\hline Papillary adenocarcinoma & 43 & 36 & 10 & \multirow[t]{4}{*}{0.999} & 46 & \multirow[t]{4}{*}{0.977} \\
\hline Tubular adenocarcinoma & 34 & 27 & 9 & & 36 & \\
\hline Signet ring cell carcinoma & 34 & 27 & 9 & & 36 & \\
\hline Mucinous adenocarcinoma & 27 & 19 & 6 & & 25 & \\
\hline \multicolumn{7}{|l|}{ Degree of differentiation } \\
\hline Poorly differentiated & 63 & 45 & 18 & \multirow[t]{3}{*}{0.557} & 63 & \multirow[t]{3}{*}{0.778} \\
\hline Moderately differentiated & 43 & 38 & 12 & & 50 & \\
\hline Well-differentiated & 32 & 26 & 4 & & 30 & \\
\hline \multicolumn{7}{|l|}{ Dukes'staging } \\
\hline A & 46 & 35 & 12 & \multirow[t]{3}{*}{0.126} & 47 & \multirow[t]{3}{*}{0.432} \\
\hline B & 56 & 47 & 20 & & 67 & \\
\hline $\mathrm{C}$ & 36 & 27 & 2 & & 29 & \\
\hline \multicolumn{7}{|l|}{ Degree of tumor infiltration } \\
\hline Non-serosal breakthrough & 41 & 18 & 3 & \multirow[t]{2}{*}{$0.006^{\mathrm{a}}$} & 21 & \multirow[t]{2}{*}{$0.002^{\mathrm{b}}$} \\
\hline Serosal breakthrough & 97 & 91 & 31 & & 122 & \\
\hline \multicolumn{7}{|l|}{ Lymph node metastasis } \\
\hline No & 105 & 81 & 24 & \multirow[t]{2}{*}{0.674} & 105 & \multirow[t]{2}{*}{0.608} \\
\hline Yes & 33 & 28 & 10 & & 38 & \\
\hline
\end{tabular}

${ }^{\mathrm{a}} \mathrm{P}<0.01$, Non-serosal breakthrough vs. Serosal breakthrough (all genotypes combined); ${ }^{\text {b }}<0.005, \mathrm{TT}+\mathrm{TC}$ vs. TT.

$59.35 \%$, respectively in the stage B group; and 20.93 and $79.07 \%$, respectively in the stage $\mathrm{C}$ group, with significant differences among the stage $\mathrm{A}, \mathrm{B}$ and $\mathrm{C}$ groups $\left(\chi^{2}=7.470 ; \mathrm{P}=0.024\right)$. No correlations were detected between the genotype distribution of AdipoR2 rs1044471 and other clinicopathological features $(\mathrm{P}>0.05$; Table V).

Haplotype analysis of rs10773989 and rs1044471 polymorphisms in the AdipoR2 gene. The linkage disequilibrium and haplotype of AdipoR2 rs10773989 and rs1044471 were analyzed using SHEsis analysis software. Linkage disequilibrium analysis revealed that the $\mathrm{D}^{\prime}$ value of rs10773989 and rs1044471 was 1 , and $\mathrm{r}^{2}$ was 0.529 , indicating linkage disequilibrium in rs10773989 and rs1044471. When the haplotype frequency was $>3 \%$, three haplotypes were formed, including CC, CT and TC, among which, the $\mathrm{CC}$ haplotype was not significantly different between the CRC patients and healthy control subjects $(\mathrm{P}>0.05)$. The CT haplotype was a protective factor for the healthy population (OR=0.667, 95\% CI=0.507-0.878; $\mathrm{P}=0.004)$; individuals who carried the $\mathrm{CT}$ haplotype were considered to be low risk for $\mathrm{CRC}$. The TC haplotype was positively correlated with the risk of $\mathrm{CRC}(\mathrm{OR}=1.404,95 \% \mathrm{CI}=1.107-1.781 ; \mathrm{P}=0.005)$ and the risk of CRC in individuals carrying the TC haplotype was increased (Table VI).
Correlations of AdipoR2 protein expression levels with AdipoR2 gene polymorphisms and clinicopathological features of CRC patients. AdipoR 2 protein was expressed in the CRC tissue samples and adjacent normal colon mucosa tissue samples, with positive staining predominantly localizing in the cytoplasm, showing light yellow, pale brown and sepia particles (Fig. 3). Correlation analysis of AdipoR2 protein expression levels in CRC tissue samples $(n=281)$ with the genotype frequencies of rs10773989 and rs1044471, and clinicopathological features revealed that there were correlations of AdipoR2 protein expression with the degree of differentiation, Dukes' staging, the degree of infiltration and lymph node metastasis (LNM) in CRC $(\mathrm{P}<0.05)$. No correlations were identified between AdipoR2 protein expression levels and other clinicopathological features ( $\mathrm{P}>0.05$; Table VII). In addition, the gene polymorphism of AdipoR2 rs10773989 was statistically associated with the AdipoR2 protein expression level $(\mathrm{P}<0.05)$.

Non-conditional logistic regression analysis of risk factors for CRC. The multivariate non-conditioned logistic regression analysis was conducted with CRC as a dependent variable, and age, gender, smoking, alcohol consumption, tumor history, BMI, TG, HDL-C and LDL-C as independent variables. The results indicated that the TT genotype of AdipoR2 rs10773989 
Table V. Correlation of the adiponectin receptor 2 rs1044471 polymorphism with clinicopathological features of patients with colorectal cancer.

\begin{tabular}{|c|c|c|c|c|c|c|}
\hline \multirow[b]{2}{*}{ Feature } & \multicolumn{3}{|c|}{ Genotype } & \multirow[b]{2}{*}{ P-value } & \multirow[b]{2}{*}{$\mathrm{CT}+\mathrm{TT}$} & \multirow[b]{2}{*}{ P-value } \\
\hline & $\mathrm{CC}$ & CT & TT & & & \\
\hline \multicolumn{7}{|l|}{ Tumor diameter $(\mathrm{cm})$} \\
\hline$<5$ & 75 & 37 & 2 & \multirow[t]{2}{*}{0.374} & 39 & \multirow[t]{2}{*}{0.989} \\
\hline$\geq 5$ & 110 & 49 & 8 & & 57 & \\
\hline \multicolumn{7}{|l|}{ Histological type } \\
\hline Papillary adenocarcinoma & 59 & 24 & 6 & \multirow[t]{4}{*}{0.501} & 30 & \multirow[t]{4}{*}{0.935} \\
\hline Tubular adenocarcinoma & 45 & 23 & 2 & & 25 & \\
\hline Signet ring cell carcinoma & 45 & 23 & 2 & & 25 & \\
\hline Mucinous adenocarcinoma & 36 & 16 & 0 & & 16 & \\
\hline \multicolumn{7}{|l|}{ Degree of differentiation } \\
\hline Poorly differentiated & 76 & 42 & 8 & \multirow[t]{3}{*}{$0.007^{\mathrm{a}}$} & 50 & \multirow[t]{3}{*}{$0.008^{b}$} \\
\hline Moderately differentiated & 58 & 34 & 1 & & 35 & \\
\hline Well-differentiated & 51 & 10 & 1 & & 11 & \\
\hline \multicolumn{7}{|l|}{ Dukes' staging } \\
\hline A & 54 & 37 & 2 & \multirow[t]{3}{*}{$0.040^{\mathrm{c}}$} & 39 & \multirow[t]{3}{*}{0.0240} \\
\hline $\mathrm{B}$ & 73 & 43 & 7 & & 50 & \\
\hline $\mathrm{C}$ & 58 & 17 & 1 & & 18 & \\
\hline \multicolumn{7}{|l|}{ Degree of tumor infiltration } \\
\hline Non-serosal breakthrough & 46 & 14 & 2 & \multirow[t]{2}{*}{0.281} & 16 & \multirow[t]{2}{*}{0.116} \\
\hline Serosal breakthrough & 139 & 72 & 8 & & 80 & \\
\hline \multicolumn{7}{|l|}{ Lymph node metastasis } \\
\hline No & 136 & 64 & 9 & \multirow[t]{2}{*}{0.580} & 73 & \multirow[t]{2}{*}{0.645} \\
\hline Yes & 49 & 22 & 1 & & 23 & \\
\hline
\end{tabular}

${ }^{\mathrm{a}} \mathrm{P}<0.01$ vs. all degree of differentiation types (all genotypes combined); ${ }^{\mathrm{b}} \mathrm{P}<0.01, \mathrm{CT}+\mathrm{TT}$ vs. TT; ${ }^{\mathrm{C}}<0.05$ vs. all Dukes' staging types (all genotypes combined).

Table VI. Comparison in haplotypes of rs10773989 and rs 1044471 polymorphisms in the adiponectin receptor 2 gene between patients with colorectal cancer (case) and healthy control subjects.

\begin{tabular}{lcccc}
\hline Haplotype & Case group (freq.) & Control group (freq.) & P-value & Odds ratio (95\% confidence interval) \\
\hline CC & $42(0.129)$ & $36(0.130)$ & 0.880 & $1.026(0.732-1.440)$ \\
CT & $84(0.258)$ & $53(0.189)$ & 0.004 & $1.499(1.139-1.974)$ \\
TC & $199(0.612)$ & $192(0.681)$ & 0.008 & $0.726(0.572-0.921)$ \\
\hline
\end{tabular}

$(\mathrm{OR}=1.434,95 \% \mathrm{CI}=1.087-1.893 ; \mathrm{P}=0.011)$ and the $\mathrm{CC}$ genotype of AdipoR2 rs1044471 (OR=1.610, 95\% CI=1.190-2.177; $\mathrm{P}=0.002)$ were independent risk factors for CRC (Table VIII).

\section{Discussion}

This present study systematically evaluated the associations between two SNPs in the AdipoR2 gene (rs10773989 and rs1044471), AdipoR2 protein expression levels and the risk of CRC. The present study indicated that the AdipoR2 rs10773989 and rs1044471 polymorphisms may be correlated with the susceptibility to CRC, that the CT haplotype is a protective factor and that the TC haplotype is a risk factor in a healthy population. This indicated that carriers of the CT haplotype had a reduced CRC risk and carriers of the TC haplotype had an enhanced CRC risk. Furthermore, the TC haplotype and positive expression of the AdipoR2 protein may increase the risk of CRC

ADIPOQ has been proposed as a biological link between obesity and various types of malignancy, such as CRC, through its actions mediated by binding and activating specific AdipoRs, including AdipoR1 and AdipoR2 (26). In addition, AdipoRs have been identified to mediate the link between ADIPOQ and activation of adenosine monophosphate (AMP)-activated protein kinase, which causes ADIPOQ to exert antiproliferative effects in cancer cases (27). The 
Table VII. Correlations of AdipoR2 protein expression with AdipoR2 genetic polymorphisms (rs10773989 and rs1044471) and clinicopathological features of patients with colorectal cancer.

AdipoR2 expression

\begin{tabular}{|c|c|c|c|c|}
\hline & \multirow[b]{2}{*}{$\mathrm{n}$} & & \multirow[b]{2}{*}{ P-value } \\
\hline & & Positive n (\%) & Negative $\mathrm{n}(\%)$ & \\
\hline \multicolumn{5}{|l|}{ rs10773989 } \\
\hline $\mathrm{TT}$ & 138 & $126(91.30)$ & $12(8.69)$ & 0.020 \\
\hline $\mathrm{TC}+\mathrm{CC}$ & 143 & $117(81.82)$ & $26(18.18)$ & \\
\hline \multicolumn{5}{|l|}{ rs1044471 } \\
\hline $\mathrm{CC}$ & 185 & $157(84.86)$ & $28(15.14)$ & 0.273 \\
\hline $\mathrm{CT}+\mathrm{TT}$ & 96 & $86(89.58)$ & $10(10.42)$ & \\
\hline \multicolumn{5}{|l|}{ Age (years) } \\
\hline$<55$ & 83 & $73(87.95)$ & $10(12.05)$ & 0.640 \\
\hline$\geq 55$ & 198 & $170(85.86)$ & $28(14.14)$ & \\
\hline \multicolumn{5}{|l|}{ Gender } \\
\hline Male & 165 & $144(87.27)$ & $21(12.73)$ & 0.642 \\
\hline Female & 116 & $99(85.34)$ & $17(14.66)$ & \\
\hline \multicolumn{5}{|l|}{ Tumor diameter $(\mathrm{cm})$} \\
\hline$<5$ & 114 & $100(87.72)$ & $14(12.18)$ & 0.615 \\
\hline$\geq 5$ & 167 & $143(85.63)$ & $24(14.37)$ & \\
\hline \multicolumn{5}{|l|}{ Histological type } \\
\hline Papillary adenocarcinoma & 89 & $74(83.15)$ & $15(16.85)$ & 0.665 \\
\hline Tubular adenocarcinoma & 70 & $61(87.14)$ & $9(12.86)$ & \\
\hline Signet ring cell carcinoma & 70 & $61(87.14)$ & $9(12.86)$ & \\
\hline Mucinous adenocarcinoma & 52 & $47(90.38)$ & $5(9.62)$ & \\
\hline \multicolumn{5}{|l|}{ Degree of differentiation } \\
\hline Poor-differentiated & 126 & $114(90.48)$ & $12(9.52)$ & 0.018 \\
\hline Moderate-differentiated & 93 & $82(88.17)$ & $11(11.83)$ & \\
\hline Well-differentiated & 62 & $47(75.81)$ & $15(24.19)$ & \\
\hline \multicolumn{5}{|l|}{ Dukes staging } \\
\hline A & 93 & 87 (93.55) & $6(6.45)$ & 0.026 \\
\hline $\mathrm{B}$ & 123 & $105(85.37)$ & $18(14.63)$ & \\
\hline $\mathrm{C}$ & 65 & $51(78.46)$ & $14(21.54)$ & \\
\hline \multicolumn{5}{|l|}{ Degree of tumor infiltration } \\
\hline Non-serosal breakthrough & 62 & $48(77.42)$ & $14(22.58)$ & 0.018 \\
\hline Serosal breakthrough & 219 & $195(89.04)$ & $24(10.96)$ & \\
\hline \multicolumn{5}{|l|}{ Lymph node metastasis } \\
\hline No & 210 & $198(94.29)$ & $12(5.71)$ & 0.001 \\
\hline Yes & 71 & $45(63.38)$ & $26(36.62)$ & \\
\hline
\end{tabular}

AdipoR2, adiponectin receptor 2.

AdipoR2 SNP rs10773989 may modulate the effects of ADIPOQ on cancer risk by regulating the protein expression of AdipoR2. It was confirmed in a previous study that SNP rs10773989 in the AdipoR2 gene was statistically associated with AdipoR2 protein expression (28). Therefore, it seems plausible that the SNPs in the AdipoR2 gene may influence the protein expression of AdipoR2, and thereby repress the antiproliferative effects of ADIPOQ in cancer cases, which leads to increased risk of CRC. Furthermore, Byeon et al (29) demonstrated that ADIPOQ levels are lower in patients with CRC when compared with healthy individuals; and its receptors, AdipoRs, expressed in adenocarcinoma and healthy colorectal tissue, may mediate its effects on cellular proliferation and apoptosis. Furthermore, in the present study, it was also revealed that the TT genotype of AdipoR2 rs10773989 and the CC genotype of AdipoR2 rs1044471 were independent risk factors for CRC. Similarly, allele C of rs10773989 and allele $\mathrm{T}$ of rs1044471 in the AdipoR2 gene were reported to demonstrate significant associations with decreased risk of cardia cancers (17). He et al (14) demonstrated that the rs12733285 C/T genotype and carriage of the A allele of rs1342387 (A/G or A/A) in AdipoRl are protective factors 
Table VIII. Non-conditional logistic regression analysis of risk factors in colorectal cancer.

$95 \%$ CI for

$\operatorname{EXP}(\beta)$

\begin{tabular}{lcccccccc}
\cline { 5 - 8 } Variable & $\beta$ & Standard error & Wald & df & P-value & Exp $(\beta)$ & Lower & Upper \\
\hline Age & 0.008 & 0.008 & 1.017 & 1 & 0.313 & 1.008 & 0.992 & 1.025 \\
Gender & 0.114 & 0.180 & 0.400 & 1 & 0.527 & 1.121 & 0.787 & 1.596 \\
Alcohol consumption & -0.458 & 0.261 & 3.082 & 1 & 0.079 & 0.633 & 0.379 & 1.055 \\
Smoking condition & -0.444 & 0.274 & 2.621 & 1 & 0.105 & 0.642 & 0.375 & 1.098 \\
Tumor history & -0.580 & 0.325 & 3.182 & 1 & 0.074 & 0.560 & 0.296 & 1.059 \\
Body mass index & -0.050 & 0.052 & 0.919 & 1 & 0.338 & 0.952 & 0.860 & 1.053 \\
Triglyceride & 0.119 & 0.080 & 2.224 & 1 & 0.136 & 1.126 & 0.963 & 1.316 \\
Low-density lipoprotein & -0.116 & 0.079 & 2.177 & 1 & 0.140 & 0.890 & 0.763 & 1.039 \\
High-density lipoprotein & -0.070 & 0.149 & 0.223 & 1 & 0.637 & 0.932 & 0.697 & 1.248 \\
rs10773989 TT & & & 8.027 & 2 & 0.018 & & & \\
$\quad$ rs10773989 TC & 0.539 & 0.199 & 7.307 & 1 & 0.007 & 1.714 & 1.160 & 2.534 \\
$\quad$ rs10773989 CC & 0.588 & 0.296 & 3.951 & 1 & 0.047 & 1.800 & 1.008 & 3.213 \\
rs1044471 CC & & & 10.243 & 2 & 0.006 & & & \\
$\quad$ rs1044471 CT & 0.421 & 0.183 & 5.271 & 1 & 0.022 & 1.524 & 1.064 & 2.183 \\
rs1044471 TT & 1.192 & 0.449 & 7.060 & 1 & 0.008 & 3.295 & 1.367 & 7.941 \\
\hline
\end{tabular}

$\beta$, partial regression coefficient; Wald, Wald statistical test (maximum likelihood estimate); df, degrees of freedom; $\operatorname{Exp}(\beta)$, $\operatorname{exponent}$ function $(\beta) ; 95 \% \mathrm{CI}, 95 \%$ confidence interval.

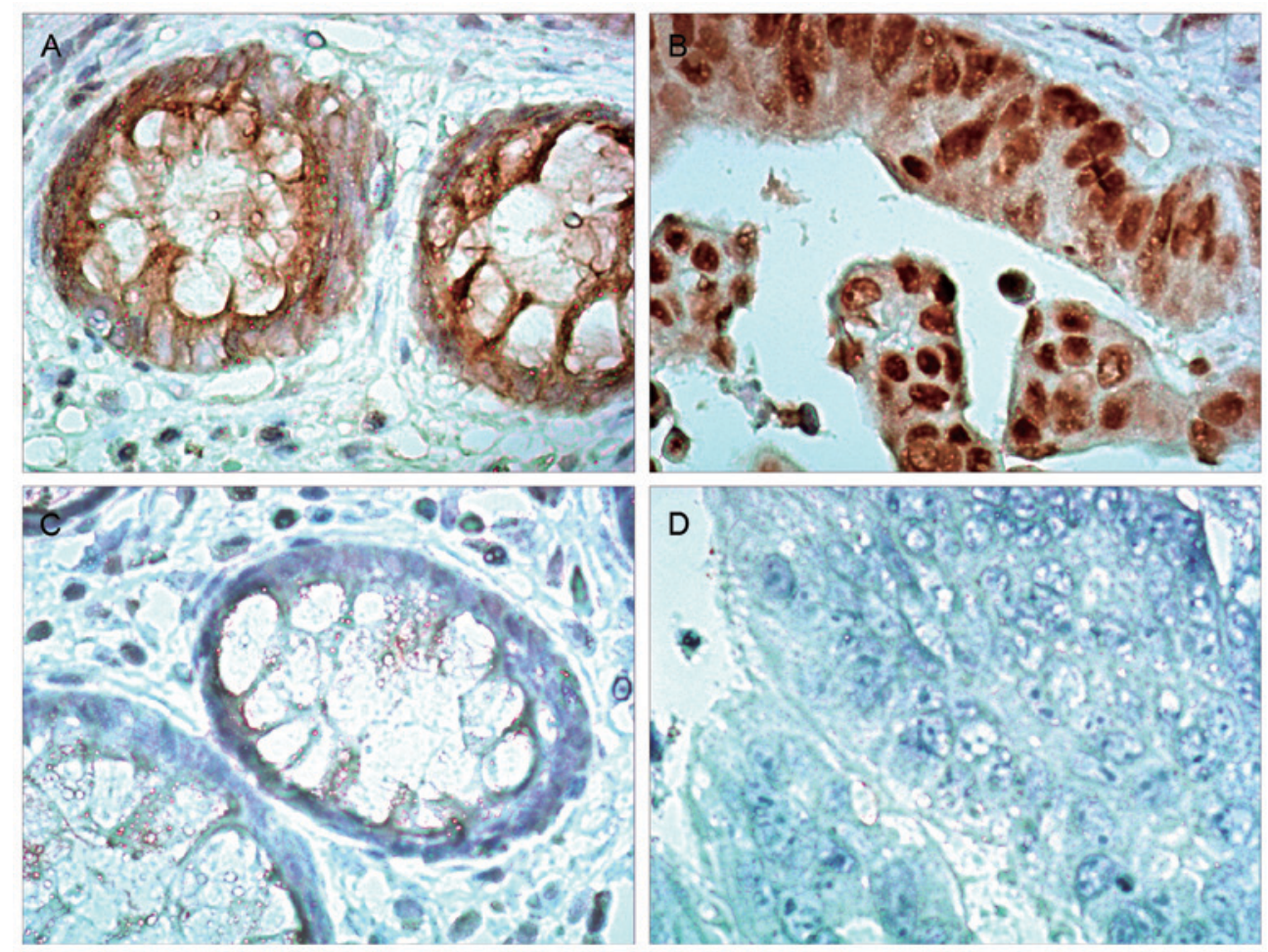

Figure 3. Immunohistochemistry results of adiponectin receptor 2 protein expression in the CRC tissue samples and adjacent normal colon mucosa tissue samples. (A) Weak positive staining and (B) positive staining in the CRC tissues. Negative control of (C) adjacent normal colon mucosa tissue samples and (D) CRC tissue samples (magnification, $\mathrm{x} 400$ ). CRC, colorectal cancer.

for CRC, while rs266729 G/C and $\mathrm{G}$ allele of $A D I P O Q$ are risk factors for CRC (14). In a meta-analysis by Ou et al (13), with a hospital-based case-control study of 341 cases and
727 control subjects, the associations between the common variants on $A D I P O Q$ (rs266729, rs822395, rs2241766 and rs1501299) and AdipoRl (rs1342387 and rs12733285) and 
CRC susceptibility were evaluated, and it was demonstrated that variant rs1342387 on AdipoR1 may be a novel CRC susceptibility factor. Ye et al (27) systematically searched case-control studies published in February 2015 examining any AdipoR1 polymorphisms and risk of any type of cancer, and suggested that the AdipoR1 rs1342387 (G/A) polymorphism may be associated with cancer risk, particularly the risk of CRC in Asian individuals (27). Al-Harithy and Al-Zahrani (26) performed a case-control study on 60 CRC patients and 60 control subjects in a Saudi population, and revealed an enhanced risk of CRC that was associated with the $276 \mathrm{~T}$ allele, and that the $\mathrm{G}$ allele at the $\mathrm{T} 45 \mathrm{G}$ polymorphism was associated with a lower CRC risk in $A D I P O Q$ (28).

In addition, the current study identified that the AdipoR2 rs10773989 polymorphism was associated with the degree of tumor infiltration, while the AdipoR2 rs1044471 polymorphism was associated with the degree of differentiation and Dukes' staging in CRC. Furthermore, AdipoR2 protein expression was associated with the degree of differentiation, Dukes' staging, the degree of tumor infiltration and LNM. These findings indicated that the SNPs of AdipoR2, rs10773989 and rs1044471, and AdipoR2 protein expression levels may be crucial in the progression of CRC. In addition, these findings may support the assumption that ADIPOQ suppresses tumor growth of CRC, as abundant AdipoR expression levels in CRC tissue may promote the anti-carcinogenic effect of ADIPOQ. By contrast, low AdipoR expression levels may facilitate CRC progression against the effects of ADIPOQ (29). In line with the present findings, Gialamas et al (26) reported that ADIPOQ levels and tissue expression of AdipoRs appeared to be associated with CRC risk and with a few clinicopathological features including advanced tumor grade, TNM stage and LNM (26).

In conclusion, the findings of the present case-control study further exemplify the role of AdipoR 2 genetic polymorphisms (rs10773989 and rs1044471) and its protein expression in colorectal carcinogenesis and advancement. Large prospective studies are warranted to confirm these observations and further investigate the potential role of AdipoR2 as a therapeutic target along with their clinicopathological implications in CRC survival.

\section{Acknowledgements}

The authors would like to thank the reviewers for their helpful comments on this manuscript.

\section{References}

1. Brenner H, Kloor M and Pox CP: Colorectal cancer. Lancet 383: 1490-1502, 2014

2. Jemal A, Siegel R, Xu J and Ward E: Cancer statistics, 2010. CA Cancer J Clin 60: 277-300, 2010

3. Toiyama Y, Okugawa Y and Goel A: DNA methylation and microRNA biomarkers for noninvasive detection of gastric and colorectal cancer. Biochem Biophys Res Commun 455: 43-57, 2014.

4. Lee JY, Chu SH, Jeon JY, Lee MK, Park JH, Lee DC, Lee JW and Kim NK: Effects of 12 weeks of probiotic supplementation on quality of life in colorectal cancer survivors: A double-blind, randomized, placebo-controlled trial. Dig Liver Dis 46 $1126-1132,2014$.
5. Migliore L, Migheli F, Spisni R and Coppedè F: Genetics, cytogenetics, and epigenetics of colorectal cancer. J Biomed Biotechnol 2011: 792362, 2011.

6. Liu L, Zhong R, Wei S, Yin JY, Xiang H, Zou L, Chen W, Chen JG, Zheng XW, Huang LJ, et al: Interactions between genetic variants in the adiponectin, adiponectin receptor 1 and environmental factors on the risk of colorectal cancer. PLoS One 6: e27301, 2011.

7. Aleksandrova K, Jenab M, Bueno-de-Mesquita HB, Fedirko V, Kaaks R, Lukanova A, van Duijnhoven FJ, Jansen E, Rinaldi S, Romieu I, et al: Biomarker patterns of inflammatory and metabolic pathways are associated with risk of colorectal cancer: Results from the European prospective investigation into cancer and nutrition (EPIC). Eur J Epidemiol 29: 261-275, 2014.

8. Vansaun MN: Molecular pathways: Adiponectin and leptin signaling in cancer. Clin Cancer Res 19: 1926-1932, 2013.

9. Khandekar MJ, Cohen P and Spiegelman BM: Molecular mechanisms of cancer development in obesity. Nat Rev Cancer 11: 886-895, 2011.

10. Cheng SP, Liu CL, Hsu YC, Chang YC, Huang SY and Lee JJ: Expression and biologic significance of adiponectin receptors in papillary thyroid carcinoma. Cell Biochem Biophys 65: 203-210, 2013.

11. Yamauchi T, Kamon J, Ito Y, Tsuchida A, Yokomizo T, Kita S, Sugiyama T, Miyagishi M, Hara K, Tsunoda M, et al: Cloning of adiponectin receptors that mediate antidiabetic metabolic effects. Nature 423: 762-769, 2003.

12. Turer AT and Scherer PE: Adiponectin: Mechanistic insights and clinical implications. Diabetologia 55: 2319-2326, 2012.

13. Ou Y, Chen P, Zhou Z, Li C, Liu J, Tajima K, Guo J, Cao J and Wang $\mathrm{H}$ : Associations between variants on ADIPOQ and ADIPOR1 with colorectal cancer risk: A Chinese case-control study and updated meta-analysis. BMC Med Genet 15: 137, 2014.

14. He B, Pan Y, Zhang Y, Bao Q, Chen L, Nie Z, Gu L, Xu Y and Wang S: Effects of genetic variations in the adiponectin pathway genes on the risk of colorectal cancer in the Chinese population. BMC Med Genet 12: 94, 2011.

15. Pechlivanis S, Bermejo JL, Pardini B, Naccarati A, Vodickova L, Novotny J, Hemminki K, Vodicka P and Försti A: Genetic variation in adipokine genes and risk of colorectal cancer. Eur J Endocrinol 160: 933-940, 2009.

16. López-Bermejo A, Botas-Cervero P, Ortega-Delgado F Delgado E, García-Gil MM, Funahashi T, Ricart W and Fernández-Real JM: Association of ADIPOR2 with liver function tests in type 2 diabetic subjects. Obesity (Silver Spring) 16: 2308-2313, 2008

17. Ye L, Zhang ZY, Du WD, Schneider ME, Qiu Y, Zhou Y, Zhou FS, Zuo XB, Chen G, Ma XL, et al: Genetic analysis of ADIPOQ variants and gastric cancer risk: A hospital-based case-control study in China. Med Oncol 30: 658, 2013.

18. Stark JR, Mucci LA, Penney KL, Dhillon P, Loda M, Sesso HD, Stampfer MJ and Ma J: Abstract A123: Common polymorphisms in adiponectin and adiponectin receptor genes and prostate cancer survival. Cancer Prev Res 3: A123, 2010.

19. Gornick MC, Rennert G, Moreno V and Gruber SB: Adiponectin gene and risk of colorectal cancer. Br J Cancer 105: 562-564, 2011.

20. Li P, Liu H, Li C, Yang B, Kong Q, Zheng W, Li B and Jia B: An updated meta-analysis of the association between ADIPOQ rs2241766 polymorphism and colorectal cancer. Tumour Biol 35: 2491-2496, 2014

21. M PN: World medical association publishes the revised declaration of Helsinki. Natl Med J India 27: 56, 2014.

22. Winawer SJ, St John DJ, Bond JH, et al: Prevention of colorectal carcinoma. Current WHO guidelines for early detection of colorectal carcinoma. World health organization collaborating center for the prevention of colorectal cancer. Leber Magen Darm 26: 139-140, 143, 1996.

23. Brown RS and Wahl RL: Overexpression of Glut-1 glucose transporter in human breast cancer. An immunohistochemical study. Cancer 72: 2979-2985, 1993.

24. Shi Y: Computer-based algorithms for multiple criteria and multiple constraint level integer linear programming. Comput Math Appl 49: 903-921, 2005.

25. Kim JH, Park MY, Kim CN, Kim KH, Kang HB, Kim KD and Kim JW: Expression of endothelial cell-specific molecule-1 regulated by hypoxia inducible factor- $1 \alpha$ in human colon carcinoma: Impact of ESM-1 on prognosis and its correlation with clinicopathological features. Oncol Rep 28: 1701-1708, 2012. 
26. Gialamas SP,Petridou ET,Tseleni-BalafoutaS,Spyridopoulos TN, Matsoukis IL, Kondi-Pafiti A, Zografos G and Mantzoros CS Serum adiponectin levels and tissue expression of adiponectin receptors are associated with risk, stage, and grade of colorectal cancer. Metabolism 60: 1530-1538, 2011.

27. Ye J, Jiang L, Wu C, Liu A, Mao S and Ge L: Three ADIPOR1 polymorphisms and cancer risk: A meta-analysis of case-control studies. PLoS One 10: e0127253, 2015.
28. Al-Harithy RN and Al-Zahrani MH: The adiponectin gene, ADIPOQ, and genetic susceptibility to colon cancer. Oncol Lett 3: 176-180, 2012.

29. Byeon JS, Jeong JY, Kim MJ, Lee SM, Nam WH, Myung SJ, Kim JG, Yang SK, Kim JH and Suh DJ: Adiponectin and adiponectin receptor in relation to colorectal cancer progression. Int $\mathrm{J}$ Cancer 127: 2758-2767, 2010. 